\title{
Supplemental Insurance Reduces Out-of-Pocket Costs in Medicare Observation Services
}

\author{
Brian J. Doyle, MD*, Susan L. Ettner, PhD², Teryl K. Nuckols, MD, MS³
}

\begin{abstract}
${ }^{1}$ Division of General Internal Medicine and Health Services Research, David Geffen School of Medicine at the University of California Los Angeles, Los Angeles, California and Veterans Affairs Greater Los Angeles Healthcare System, Los Angeles, California; ${ }^{2}$ Division of General Internal Medicine and Health Services Research, David Geffen School of Medicine at the University of California Los Angeles, Los Angeles, California and Department of Health Policy and Management, UCLA Fielding School of Public Health, Los Angeles, California; ${ }^{3}$ Division of General Internal Medicine, Department of Medicine, Cedar-Sinai Medical Center, Los Angeles, California, and the RAND Corporation, Santa Monica, California.
\end{abstract}

Up to $10 \%$ of the acutely ill patients in hospitals today are not admitted, but cared for under outpatient "observation." 1,2 Hospitals use observation services to replace inpatient services for patients who do not meet inpatient illness standards. Use of this technique for Medicare beneficiaries has grown in recent years, and future policy changes may further increase the percentage of hospital stays classified as observation. ${ }^{3,4}$

Increased use of observation services has costsharing implications for Medicare beneficiaries. Because hospital observation stays are paid through Medicare's outpatient (Part B) rather than inpatient (Part A) benefit, beneficiaries do not have an out-ofpocket maximum per hospital stay. ${ }^{3}$ Although prior analyses documented mean out-of-pocket costs of $\$ 400$ to $\$ 600$ per stay, out-of-pocket costs may exceed the Part A deductible and leave beneficiaries responsible for hospital costs that may have been reimbursed by Part A in an inpatient stay. ${ }^{5-7}$ Approximately $6 \%$ to $10 \%$ of Medicare observation stays result in out-of-pocket costs exceeding the Part A deductible nationally, and recent work in this journal documented that $26.6 \%$ of beneficiaries with repeat observation stays within a 60 -day period may pay more than the 1-time deductible-based payment that beneficiaries are responsible for under Medicare Part A. ${ }^{5-7}$

However, prior analyses of beneficiary out-ofpocket costs did not account for supplemental insurance payments. Approximately $80 \%$ to $90 \%$ of feefor-service Medicare beneficiaries who use either a private (Medigap or employer based) or state-based (Medicaid or other plans) supplemental insurance plan. ${ }^{8-10}$ The effect of supplemental insurance on outof-pocket costs has been documented for inpatient stays, yet has not been explored for observation

\footnotetext{
*Address for correspondence and reprint requests: Brian Doyle, MD, 911 Broxton Plaza, Los Angeles, CA 90024; Telephone: 267-270-2117; E-mail: bdoyle@mednet.ucla.edu

Additional Supporting Information may be found in the online version of this article.

Received: November 15, 2015; Revised: February 4, 2016; Accepted: February 9, 2016

2016 Society of Hospital Medicine DOI 10.1002/jhm.2588

Published online in Wiley Online Library (Wileyonlinelibrary.com).
}

stays. ${ }^{9}$ We sought to describe Medicare beneficiaries' out-of-pocket costs by accounting for payments from all insurers.

\section{METHODS}

We obtained payment data from 2 affiliated hospitals for all Medicare observation hospital stays between April 2013 and March 2014. Stays insured by Medicare Advantage plans (Part C) were excluded, and charges from skilled nursing facility (SNF) stays were not available. Although the exact origin of each stay was not available, the majority of stays at these hospitals came from emergency visits, direct placement from outpatient providers, and postoutpatient procedural monitoring. The dataset included charges, insurance adjustments and payments from all sources, diagnoses, and demographics. Insurance adjustments represented the reductions applied to total stay charges by each insurer in congruence with their contract with the health system. Our dataset included charges for all hospital materials and services usually billed under Part A, including medications. Out-of-pocket costs were calculated by subtracting insurance adjustments and payments from the total charges for each stay. To identify potential cost-shifting from Medicare to beneficiaries, we compared out-of-pocket costs to the Part A deductible (\$1184 for stays in 2013 and $\$ 1216$ for 2014). Household income data were estimated using zip code and Internal Revenue Service data for 2013. ${ }^{11}$

The University of California Los Angeles institutional review board approved this study. Statistical significance was calculated using a 2 -tailed unpaired $t$ test for means and $\chi^{2}$ for percentages.

\section{RESULTS}

There were 2029 total observation stays during the study period, representing $5.0 \%$ of all discharges from both hospitals. Medicare beneficiaries accounted for 722 of those observation stays. Among the 498 finalized Medicare observation stays, the median patient age was 73 years, and median household income was $\$ 50,591$. The median length of stay was 25 hours, with $1.8 \%$ of stays lasting longer than 2 midnights. Seventy percent of beneficiaries had private supplemental insurance, whereas $6 \%$ had state-based supplemental plans. Table 1 presents detailed costs. Out-of- 
TABLE 1. Insurer Payments and Beneficiary Out-ofPocket Costs

\begin{tabular}{lccc}
\hline & \multicolumn{3}{c}{ Medicare Stays, $N=498$} \\
\cline { 2 - 4 } & Mean (SD) & Median (IQR) & Range \\
\hline Payments by Medicare & $\$ 2,533(2,883)$ & $\$ 1521(1,898)$ & $\$ 4-\$ 29,633$ \\
Payments by supplemental insurers & & & \\
$\quad$ Private insurers $(\mathrm{N}=351)$ & $\$ 454(384)$ & $\$ 324(332)$ & $\$ 0-\$ 2,590$ \\
$\quad$ State-based insurers $(\mathrm{N}=29)$ & $\$ 222(402)$ & $\$ 43(102)$ & $\$ 2-\$ 1,229$ \\
Beneficiary out-0f-pocket costs & & & \\
$\quad$ Without supplemental insurer $(\mathrm{N}=118)$ & $\$ 537(1,557)$ & $\$ 286(440)$ & $\$ 0-\$ 16,196^{*}$ \\
$\quad$ With private supplemental & $\$ 45(414) \dagger$ & $\$ 0.39(16)$ & $\$ 0-\$ 7,670^{*}$ \\
insurer ( $=351)$ & & & \\
With state-based supplemental & $\$ 168(412)$ & $\$ 0.15(27)$ & $\$ 0-1,870^{*}$ \\
insurer ( $(\mathrm{N}=29)$ & & &
\end{tabular}

NOTE: Abbreviations: IQR, interquartile range; SD, standard deviation. *Out-of-pocket costs in this study represent the maximum possible value. Hospitals often write off excessive costs or they remain uncollected. ${ }^{14}+P \leq 0.01$ compared to stays without supplemental insurance.

pocket costs ranged from $\$ 0$ to $\$ 16,196$. Stays without supplemental insurance had mean and median out of pocket costs of $\$ 537$ and $\$ 286$, respectively. The mean out-of-pocket costs for stays with private supplemental insurance decreased to $\$ 45(P<0.01)$ and $\$ 168(P=$ 0.21 ) for stays with state-based supplemental insurance, with a median below $\$ 1$ for both. On average, beneficiaries without supplemental insurance were responsible for \$654 less than the Part A deductible. Thirteen beneficiaries had multiple finalized stays within 60 days, with a mean out-of-pocket cost of $\$ 119$, median of $\$ 20$, and 1 stay produced an out-of-pocket cost exceeding the Part A deductible. An additional 224 Medicare stays not finalized because of missing supplemental payments had a mean out-of-pocket cost of \$125 ( $P<$ 0.01 ) and median of $\$ 5$ after applying supplemental insurer adjustments (not shown in Table 1).

A minority of observation stays produced out-ofpocket costs exceeding the Part A deductible. Those percentages were $7.6 \%$ for stays without a supplemental insurer, $3.5 \%(P<0.01)$ for stays with a state-based supplemental insurer, and $0.3 \%(P<$ 0.01 ) for stays with a private supplemental insurer. Of the 224 nonfinalized Medicare stays, $1.3 \%(P<$ 0.01) exceeded the Part A deductible after supplemental insurer adjustments.

\section{DISCUSSION}

This study demonstrates that supplemental insurance can dramatically reduce Medicare beneficiaries' outof-pocket costs in observation services. Mean out-ofpocket costs of $\$ 45$ and $\$ 168$ for stays with private and state-based supplemental insurer plans are significantly lower than prior estimates calculated without supplemental insurance information, as are the percentages of stays with out-of-pocket costs exceeding the Part A deductible, at $0.3 \%$ and $3.5 \%$, respectively. ${ }^{5-7}$ Because the majority of Medicare beneficiaries use supplemental insurance, excessive out-ofpockets in observation services may occur less fre- quently than previously reported. ${ }^{9,10}$ Clinicians concerned about excessive out-of-pocket costs for Medicare beneficiaries can be reassured they are usually modest for beneficiaries with supplemental insurance.

This study's mean out-of-pocket cost and percentage of stays with out-of-pocket costs exceeding the Part A deductible for beneficiaries without supplemental insurance are similar to results from prior national analyses performed without supplemental insurer information. ${ }^{5-7}$ But this study was limited by a small sample size from 2 affiliated hospitals, with few repeat observation stays within a 60-day period. In addition, posthospitalization SNF fees were not included, which traditionally have been a significant source of out-ofpocket costs in observation services. ${ }^{3,7}$ Populations with supplemental insurance treated elsewhere may incur hospital out-of-pocket costs differing from these results due to dissimilarities in the presence and quality of supplemental insurance.

However, most Medigap plans are federally regulated to cover the majority of out-of-pockets unpaid by Medicare. ${ }^{12}$ Medicaid plans usually place limits on outof-pocket costs, and any other state or employer-based supplemental plans will also reduce out-of-pocket costs. ${ }^{13}$ Thus, it is likely accurate to assume mean observation services out-of-pocket costs for hospital fees are lower than previously reported by national analyses performed without supplemental insurance information. Attempts at estimating beneficiary out-ofpocket costs in the future should account for supplemental insurance adjustments and payments.

\section{Acknowledgements}

The authors thank Andrew Kaufman for his work in obtaining these data.

Disclosures: Dr. Doyle's time was supported by a National Research Service Award from the National Institutes of Health and administered through the University of California Los Angeles. Drs. Ettner and Nuckols received no support for this work. There are no conflicts of interest to report.

\section{References}

1. Sheehy AM, Graf B, Gangireddy S, et al. Hospitalized but not admitted: characteristics of patients with "observation status" at an academic medical center. JAMA Intern Med. 2013;173(21):1991-1998.

2. Coffey R, Barret M, Steiner S. Final report observation status related to hospital records. Available at: https://www.hcup-us.ahrq.gov/ reports/methods/FinalReportonObservationStatus_v2Final.pdf. Published September 27, 2002.

3. Cassidy A. The two-midnight rule. Health Policy Briefs. Health Affairs website. Available at: http://www.healthaffairs.org/healthpolicybriefs/ brief.php?brief_id=133. Published January 22, 2015.

4. Feng Z, Wright B, Mor V. Sharp rise in Medicare enrollees being held in hospitals for observation raises concerns about causes and consequences. Health Aff (Millwood). 2012;31(6):1251-1259.

5. Kangovi S, Cafardi SG, Smith RA, Kulkarni R, Grande D. Patient financial responsibility for observation care. J Hosp Med. 2015; 10(11):718-723.

6. Lind K, Noel-Miller C, L. Zhao CS. Observation status: Financial Implications for Medicare Beneficiaries. AARP Public Policy Institute. Available at: http://www.aarp.org/content/dam/aarp/ppi/2015/Hosp Obs Financial Impact Paper.pdf. Published April 2015.

7. Wright S. Hospitals' use of observation stays and short inpatient stays for Medicare beneficiaries. Department of Health and Human Services. Office of Inspector General. Available at: https://oig.hhs.gov/oei/ reports/oei-02-12-00040.pdf. Published July 29, 2013.

8. Laschober M. Trends in Medicare supplemental insurance and prescription drug benefits, 1996-2001: Data update. Available at: http:// 
www.kff.org/medicare/upload/Trends-in-Medicare-SupplementalInsurance-and-Prescription-Drug-Benefits-1996-2001Data-Update.pdf.

9. Noel-Miller CP. Medicare beneficiaries' out-of-pocket spending for health care. AARP Public Policy Institute. Available at: http://www. aarp.org/content/dam/aarp/research/public_policy_institute/health/ medicare-beneficiaries-out-of-pocket-spending-AARP-ppi-health.pdf. Published May 2012.

10. Cubanski J, Swoope C, Boccuti C, et al. A primer on Medicare: key facts about the Medicare program and the people it covers. What types of supplemental insurance do beneficiaries have? Kaiser Family Foundation website. Available at: http://kff.org/report-section/a-primer-on-medicare-what-types-of-supplemental-insurance-do-beneficiaries-have. Published March 20, 2015.
11. SOI tax stats-individual income tax statistics-ZIP code data (SOI). Available at: https://www.irs.gov/uac/SOI-Tax-Stats-Individual-IncomeTax-Statistics-ZIP-Code-Data-(SOI). Accessed January 1, 2016.

12. How to compare Medigap policies. Medicare.gov website. Available at: https://www.medicare.gov/supplement-other-insurance/comparemedigap/compare-medigap.html.

13. Cost sharing out of pocket costs. Medicaid.gov website. Available at: https://www.medicaid.gov/medicaid-chip-program-information/by-topics/ cost-sharing/cost-sharing-out-of-pocket-costs.html. Accessed January 26, 2016.

14. Staiti AB, Hurley RE, Cunningham PJ. Balancing margin and mission: hospitals alter billing and collection practices for uninsured patients. Issue Brief Cent Stud Health Syst Change. 2005;(99):1-4. 